\title{
Spontaneous Skin Tumor in a Companion Dwarf Rabbit
}

\author{
Pablo Eduardo Martino', Eduardo Jorge Gimeno², Miguel Angel Píscopo', Cecilia María Netri', \\ María Florencia Unzaga' \& Javier Aníbal Origlia'
}

\begin{abstract}
Background: Scarce reports have been published worldwide on primary skin tumours in pet rabbits. Trichoblastoma is a rare benign neoplasm of animals and humans derived from or reduplicating the primitive germ of embryonic follicular development; it was previously classified as a basal cell tumor, meanwhile its malignant counterpart is referred to as malignant trichoblastoma or trichoblastic carcinoma. Neoplasms of domestic animals that once were lumped into the broad histologic diagnosis of basal cell tumors have since been split into distinct entities, dependent on evidence of differentiation, although a cytologic diagnosis of basal cell tumor continues to be used indistinctly to represent the large, heterogeneous group of epidermal, trichofollicular, and adnexal skin tumors with basal cell characteristics. Hereby, it is described the morphological and immunohistochemical findings of a case of spontaneous malignant trichoblastoma on a domestic companion rabbit from South America.

Case: A 4-year-old, male black dwarf rabbit (Oryctolagus cuniculus) was brought to the Veterinary College when appeared with a sudden appearance of a grayish nodular subcutaneous mass measuring $3.0 \times 2.0 \mathrm{~cm}$ and located on left tarsal zone, during march 2014. A case of malignant trichoblastoma with a predominance of trabecular architecture was diagnosed based on morphologic and microscopic results. Fine-needle aspiration, histopathology and immunohistochemistry were performed on the ulcerated mass. The mass was sectioned and stained with hematoxylin and eosin (HE), periodic acid-Schiff (PAS) and Masson trichrome stain. Replicate serial sections from the paraffin-embedded tissue blocks were immunostained for cytokeratin (AE1/AE3), smooth muscle actin, polyclonal nestin, desmin and myoglobin, using commercial kits. Mayer's hematoxylin solution was used as a counterstain. Negative controls were produced by substituting the primary antibody with 5\% bovine serum albumin in phosphate buffered saline. To assess mitotic activity, mitoses count in 10 randomly selected high-power fields was done. Diagnoses was made in accordance with the recommendations for the histological classification of tumors of domestic animals. After surgical excision, the animal remains healthy.

Discussion: Epithelial nonviral skin neoplasms are uncommon in rabbits and have been cited in sporadic case reports or few case series including basal cell tumors and squamous cell carcinomas. All these cases emphasized the need for cytologic criteria and nomenclature on rabbit tumors that better reflect potential variation in tissue differentiation. As a consequence, based on limited current knowledge, the practitioner is left to make decisions for diagnostics and therapeutics in these cases based upon current recommendations for other companion animals with adjustments for lagomorph physiology. This tumor, though variable in size ( 0.2 to $10 \mathrm{~cm}$ in diameter) in domestic animals (i.e., older dogs and cats), it most often appears as a solitary, well-circumscribed hairless mass in the skin, and occasionally ulcerated. The pathological data, that included tumor location, gross appearance, tumor size, growth pattern, cellular atypia, mitosis and immunohistochemistry studies, led to the malignant trichoblastoma diagnosis and these features concurred to those described in the literature. Increasing number of sporadic or induced tumors may be expected in pet rabbits in the veterinary clinic, as these animals have a high consideration among the people, and also they live longer (natural life span range: 5-10 years) than wild or farmed rabbits.
\end{abstract}

Keywords: rabbit, malignant trichoblastoma, tumor. 


\section{INTRODUCTION}

Information on skin tumors in the literature is lacking or limited for rabbits $[4,7,12]$ and, as a consequence, there is a lack of information regarding some subjects aimed at international standardization of tumor nomenclature, classification, and diagnostic criteria. In fact, Von Bomhard et al. [18] reported the first retrospective analysis on skin neoplasia in pet rabbits in U.S.A., but these conditions are incompletely known in some regions of the world.

Neoplasms of domestic animals that once were lumped into the broad histologic diagnosis of basal cell tumors have since been split into distinct entities, dependent on evidence of differentiation, although a cytologic diagnosis of basal cell tumor continues to be used indistinctly to represent the large, heterogeneous group of epidermal, trichofollicular, and adnexal skin tumors with basal cell characteristics [2,10].

For diagnosis of a skin tumor, a complete history of the animal's health, including the nature of the symptoms and a thorough physical examination, should be provided to the veterinarian [3]. Also, a fine needle aspiration cytology, whenever possible can be useful, but for definitive and differential diagnosis, however, a diagnostic procedure as histopathologic and immunohistochemical examination is mandatory $[1,11]$. The aim of this study is to enrich the pathological aspects of this entity described on rabbits.

\section{CASE}

A 4-year-old, male black dwarf rabbit (Oryctolagus cuniculus) was brought to the Veterinary College by his owner when appeared with a sudden appearance of a grayish nodular subcutaneous mass measuring 3.0 $\mathrm{x} 2.0 \mathrm{~cm}$ and located on left tarsal zone, during march 2014. A fine needle aspiration cytology was made with a 27 gauge 1.5 inch needle attached to a syringe. The material was forced onto a glass slide, spread into a thin film and then stained to identify cells with Romanowsky technique. The mass was then surgically excised with wide margins, immediately fixed in $10 \%$ neutral buffered formalin, routinely processed, and embedded in paraffin.

Tissue sections were prepared for histologic and immunohistochemical investigation. The mass was sectioned and stained with hematoxylin and eosin (HE), periodic acid-Schiff (PAS) and Masson trichrome stain. Replicate serial sections from the paraffin-embedded tissue blocks were immunostained for cytokeratin $(\mathrm{AE} 1 / \mathrm{AE} 3)^{1}$, smooth muscle actin ${ }^{2}$, polyclonal nestin ${ }^{3}$, desmin ${ }^{2}$ and myoglobin ${ }^{1}$, using commercial kits. Mayer's hematoxylin solution was used as a counterstain. According to Petterino et al. [12], positive and negative control tissue sections were run in parallel. Negative controls were produced by substituting the primary antibody with $5 \%$ bovine serum albumin in phosphate buffered saline. All tissue sections were evaluated by light microscopy. To assess mitotic activity, mitoses count in 10 randomly selected high-power fields was done. Diagnoses was made in accordance with the recommendations for the histological classification of tumors of domestic animals $[5,9,11]$.

Macroscopically, there was an ulcerated mass, anatomically located on the tarsal zone of the left forelimb (Figure 1). After excision, no local recurrence or metastasis has been reported so far. Needle aspiration was of good quality and showed a population of basophilic epithelial cells with medium vesicular nuclei, poorly differentiated and sometimes moderately anaplastic morphology reminiscent of the progenitor cells of the epidermis and adnexa along with some evidence of atypia. Histologic examination revealed a solid encapsulated mass of gland-like tumoral nests of basophil isomorphic epithelial cells that showed oval hyperchromatic nuclei, scant cytoplasm, prominent nucleoli, and frequent cellular atipia and mitosis (Figures $2 \& 3$ ). These neoplastic cells were separated by interlaced trabecules of connective tissue stroma and basal membrane structures of heavy eosinophilic stain, that led to a diagnosis of malignant trichoblastoma (subtype trabecular).

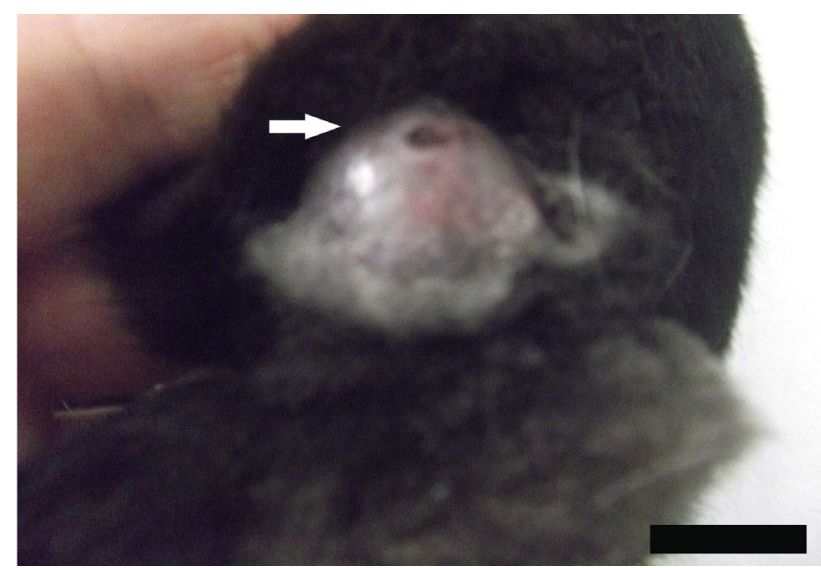

Figure 1. A grayish nodular subcutaneous mass of $3 \times 2 \mathrm{~cm}$ anatomically located on left tarsal zone of the left forelimb, showing ulceration (arrow). [Bar $=1 \mathrm{~cm}]$. 


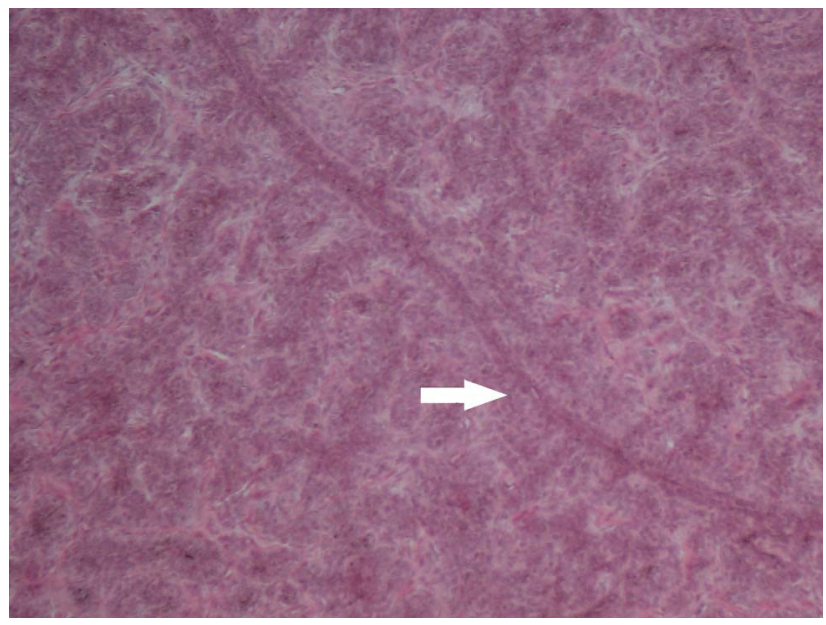

Figure 2. Malignant trichoblastoma, subtype trabecular: tumoral nests of neoplastic basophil isomorphic cells separated by interlaced trabecules of connective tissue stroma and basal membrane structures (arrow). HE. [Bar $=100 \mu \mathrm{m}]$.

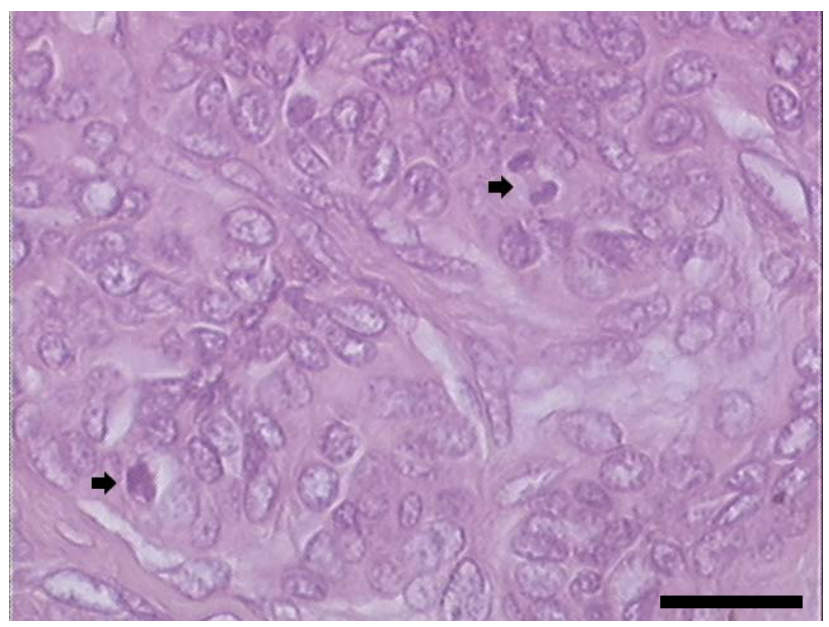

Figure 3. Neoplastic basaloid cells with oval hyperchromatic nuclei and scant cytoplasm. and showing frequent cellular atipia and mitosis (arrows). HE. [Bar $=50 \mu \mathrm{m}]$.

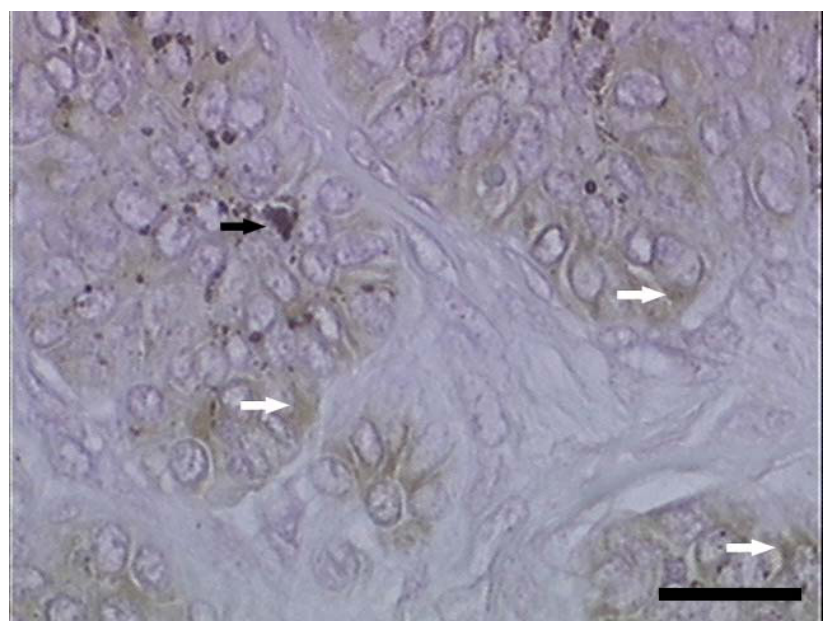

Figure 4. Immunostaining of cytokeratin (AE1/AE3) in the tumor tissue, showing positivity on the neoplastic epithelial cells (white arrows). Black arrow indicates melanin deposits. [Bar $=50 \mu \mathrm{m}]$.
Immunohistochemical studies demonstrated that the neoplastic cells were consistently positive with primary antibodies specific for epithelial cells (cytokeratin (AE1/AE3) [Figure 4], and negative for desmin, vimentin, alpha smooth muscle actin, myoglobin and nestin.

\section{DISCUSSION}

Few studies have been published concerning neoplasms in rabbits $[1,12,18]$. In fact, epithelial nonviral skin neoplasms are uncommon in rabbits and have been cited in sporadic case reports or few case series including basal cell tumors and squamous cell carcinomas [6,8,13,15-17]. All these cases emphasized the need for cytologic criteria and nomenclature on rabbit tumors that better reflect potential variation in tissue differentiation [2]. As a consequence, based on limited current knowledge, the practitioner is left to make decisions for diagnostics and therapeutics in these cases based upon current recommendations for other companion animals with adjustments for lagomorph physiology [7]. Particularly, malignant trichoblastoma is unusual and even more scarcely described in animals or humans $[9,11]$. The major retrospective study of cutaneous neoplasms in pet rabbits was made in Philadelphia, and the most common diagnoses were benign trichoblastoma but only few basal cell carcinomas were counted [18]. Recently, a collision tumour consisting of malignant trichoblastoma and melanosarcoma in a rabbit was reported [4].

Clinical and histopathologic investigations of this case supported the diagnosis of a malignant trichoblastoma, formerly described as monomorphic basal cell adenoma of solid type $[4,5,9]$. This tumor, though variable in size $(0.2$ to $10 \mathrm{~cm}$ in diameter $)$ in domestic animals (i.e., older dogs and cats), it most often appears as a solitary, well-circumscribed hairless mass in the skin, typically located on head, neck, shoulders or forelimbs, and is occasionally ulcerated [14]. This case concurred with this morphologic characteristic [4], along with the histologic pattern of the trabecular subtype [4,5]. The primary cause of this neoplasm is difficult to establish, and after surgically excised, the rabbit kept its good health. According to the literature, a complete excision of a benign trichoblastoma is curative, but prognosis may be severe in malignant cases $[9,15]$. Solar injury is a common cause of these neoplasms derived from basal cells in people, but its 
role in inducing basal cell tumors of other animals is unknown, so the underlying cause is currently unknown in domestic animals $[9,11]$.

Because rabbits are increasing in popularity as companion animals, they can be expected to live longer (natural life span range: 5-10 years) than wild rabbits and rabbits raised for meat and fur; therefore, more cases of sporadic or induced neoplasms may be expected in pet rabbits in the future $[7,12,16]$.
MANUFACTURERS

${ }^{1}$ Dako Denmark A/S. Glostrup, Denmark.

${ }^{2}$ Ventana Medical System S.A. Illkirch, France.

${ }^{3}$ Millipore Corporation. Billerica, MA, U.S.A.

Ethical approval. All procedures, treatments and animal care were approved by the Animal Welfare Committee of the UNLPVeterinary College (CICUAL protocol No.42-2-14E).

Declaration of interest. The authors report no conflicts of interest.

\section{REFERENCES}

1 Barthold S.W. \& Percy H.P. 2016. Pathology of laboratory rodents and rabbits. 4th edn. Ames: Wiley-Blackwell, 384p.

2 Bohn A.A., Wills T. \& Caplazi P. 2006. Basal cell tumor or cutaneous basilar epithelial neoplasm ? Rethinking the cytologic diagnosis of basal cell tumors. Veterinary Clinical Pathology. 35(4): 449-453.

3 Dithers R.W. \& Walsh K.M. 1984. Feline basal cell tumors: a review of 124 cases. Veterinary Pathology. 21(1): 51-56.

4 Golbar H.M., Izawa T., Kuwamura M., Fujita D., Sasai H. \& Yamate J. 2014. A collision tumour consisting of malignant trihoblastoma and melanosarcoma in a rabbit. Journal of Comparative Pathology. 151(1): 63-66.

5 Goldschmidt M.H., Dunstan R.W., Stannard A.A., von Tscharner C., Walder E.J. \& Yager J.A. 1998. Histological classification of epithelial and melanocytic tumors of skin of domestic animals. 2nd edn. Washington: Armed Forces Institute of Pathology \& the World Health Organization, 106p.

6 Groth W. 1955. Basaliome der Haut beim Hund und Kaninchen. Zeitschrift für Krebsforsch. 60(3): 361-372.

7 Heatley J.J. \& Smith A.N. 2004. Spontaneous neoplasms of lagomorphs. Veterinary Clinics of North America: Exotic Animal Practice. 7(3): 561-577.

8 Li X. \& Schlafer D.H. 1992. A spontaneous skin basal cell tumor in a black French minilop rabbit. Laboratory Animal Science. 42(1): 94-95.

9 Meuten D.J. 2008. Tumors in Domestic Animals. 4th edn. Ames: Iowa State Press, 608p.

10 Mayer J. 2015. Non-infectious diseases of rabbits. In: Porter R.S. \& Kaplan K. (Eds). The Merck Veterinary Manual online. Merck Sharp \& Dohme Corp., New Jersey: Whitehouse Station, New Jersey. [fonte:<http://www.merckvetmanual.com.>]

11 Mineshige T., Yasuno K., Sugahara G., Tomishita Y., Shimokawa N., Kamiie J., Nishifuji K. \& Shirota K. 2014. Trichoblastoma with Abundant Plump Stromal Cells in a Dog. Journal of Veterinary Medical Science. 76(5):735-739.

12 Petterino C., Modesto P., Strata D., Vascellari M., Mutinelli F., Ferrari A. \& Ratto A. 2009. A case of interscapular fibrosarcoma in a dwarf rabbit (Oryctolagus cuniculus). Journal of Veterinary Diagnostic Investigation. 21(6): 900-905.

13 Roccabianca P., Ghisleni G. \& Scanziani E. 1999. Simultaneous seminoma and interstitial cell tumour in a rabbit with a previous cutaneous basal cell tumour. Journal of Comparative Pathology. 121(1): 95-99.

14 Rostami M., Tateyama S., Uchida K., Naitou H., Yamaguchi R. \& Otsuka H. 1994. Tumors in domestic animals examined during a ten-year period (1980 to 1989) at Miyazaki University. Journal of Veterinary Medical Science. 56(2): 403-405.

15Sawyer D.R., Bunte R.M. \& Page D.G. 1997. Basal cell adenoma in a rabbit. Journal of the American Association for Laboratory Animal Science. 36(1): 90-91.

16 Quesenberry K. \& Carpenter J.W. 2012. Ferrets, Rabbits and Rodents: Clinical Medicine and Surgery. 3rd edn. St. Louis: Elsevier Saunders, 608p.

17 Weisbroth S.H. 1994. Neoplastic disease. In: Manning P.J., Ringler D.H. \& Newcomer C.E. (Eds). Biology of the laboratory rabbit. 2nd edn. San Diego: Academic Press, pp.259-292.

18 Von Bomhard W., Goldschmidt M.H. \& Shofer F.S. 2007. Cutaneous neoplasms in pet rabbits: a retrospective study. Veterinary Pathology. 44(5): 579-588. 